\title{
Sostenibilidad y participación ciudadana: el audiovisual como proceso de creación y transformación colectiva. Una conversación entre David Fernández y Silvia Cepero ${ }^{1}$
}

\author{
Jorge Llanes (editor) ${ }^{1, \mathrm{a},{ }^{*}}$, Carme Mayugo (moderadora) ${ }^{2, \mathrm{~b},{ }^{* *}}$ \\ ${ }^{1}$ Universidade de Santiago de Compostela | Teleduca, España \\ ${ }^{2}$ Universidade de Santiago de Compostela | Teleduca, España \\ a jllanesjo@gmail.com ${ }^{\mathrm{b}}$ teleduca@teleduca.org
}

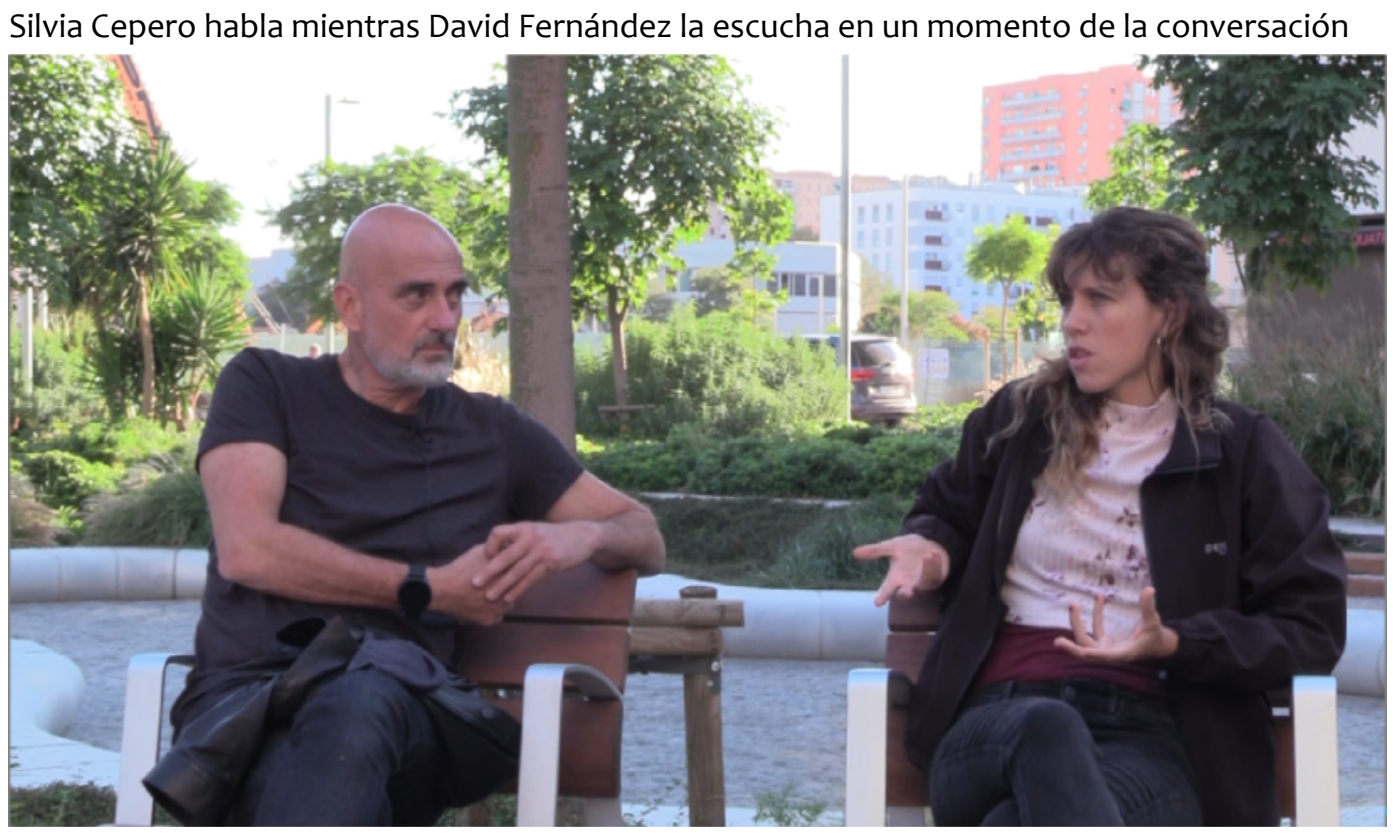

Barcelona ha sido, aún es, un paradigma en el que se miran no pocas ciudades que ambicionan llegar a tener una organización ciudadana de base tan dinámica e influyente como la de la capital catalana. De otra parte, esta ciudad mediterránea ha sido representada innúmerables veces a través de potentes imágenes que intentan resignificar su contrastada identidad. RICD ha reunido a dos creadores audiovisuales que, a lo largo de su trayectoria, han puesto su mirada en la ciudad y su ciudadanía: David Fernández y Silvia Cepero, que conversan con Carme Mayugo sobre el audiovisual como herramienta de ciudadanía; sobre un audiovisual esencialmente participativo que pretende construir procesos y relatos transformadores, que hace emerger nuevas visibilidades y transforma el marco democrático desde la participación colectiva. Fernández y Cepero recorren los complejos 
espacios sociales donde se dirime la noción de sostenibilidad de la ciudad, ante la urgencia que imponen los Objetivos de Desarrollo Sostenible (ODS) y su retórica hegemónica, señalando a aquellos actores y agencias que son favorecidas o deslegitimadas a través de la construcción de dicho relato.

En este sentido, la conversación afronta la sostenibilidad y los procesos de participación ciudadana como una cuestión que exige una doble perspectiva: una realidad social material y, por otro lado, un relato que interpela - y quizás pueda transformar - dicha materialidad. David Fernández y Silvia Cepero afrontan, desde su experiencia como realizadores audiovisuales, esta difícil tensión entre las dos caras de la misma moneda. Ambos trazan una línea argumental que, aunque ofrece distintas perspectivas y posicionamientos, converge en un punto común: la creación audiovisual y la participación colectiva debe entenderse y enfocarse como un proceso con valor en sí mismo. Así, se trata de subrayar el valor que ofrece la interacción entre personas y comunidades "en el momento de la creación", en lugar de poner el foco en "el producto final de la creación". Sin embargo, este punto de partida abre un dilema relevante y decisivo: ¿Es suficiente la "intención sin un cambio de paradigma"? ¿Tiene capacidad el audiovisual para desarrollar agencias sociales materiales o se limita a un acto creativo de carácter experimental?

\section{LA CIUDAD Y SUS MÁRGENES: PROCESOS DE PARTICIPACIÓN}

Carme Mayugo (CM): Comenzaremos la charla compartiendo reflexiones acerca de las posibilidades de Barcelona para cumplir las expectativas de los ODS y convertirse en una ciudad capaz de afrontar el reto de la sostenibilidad y favorecer la calidad de vida de las personas y comunidades. ¿Cuáles son las oportunidades y fortalezas que presenta Barcelona?

Silvia Cepero (SC): Uno de los activos potenciales de Barcelona es su tejido social y organizado de base (asociaciones, entidades, colectivos, etc.), que siempre ha emprendido y liderado iniciativas de lucha y de cambio. Si encuentro algo fiable en la posibilidad de creer en una Barcelona sostenible tendría mucho que ver con la capacidad de autoorganización de base de este tejido asociativo. También debemos señalar al Ayuntamiento de Barcelona por sus intentos de desarrollar políticas institucionales más locales como, por ejemplo, el Plan de Barrios. En cualquier caso, el principal activo se encuentra en la movilización de las personas conscientes de que es necesaria una Barcelona y un mundo más sostenible.

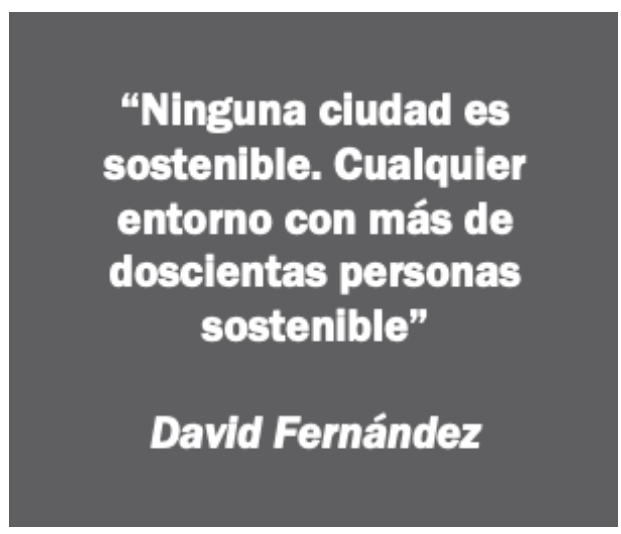


David Fernández (DF): En primer lugar, me gustaría matizar que, desde mi punto de vista, cualquier entorno con más de doscientas personas viviendo juntas no es sostenible. Aunque Barcelona es una realidad que me queda muy lejana [en el tiempo], diría que, ahora mismo, no es una ciudad referente. Tengo una mirada de Barcelona que está muy condicionada por la última época en la que estuve aquí (hace más de diez años) y, por tanto, no estoy capacitado para reflexionar sobre el tejido que existe ahora mismo o las capacidades de la ciudad para ser sostenible hoy en día. En cualquier caso, yo no la veo sostenible porque una ciudad no es sostenible. Un lugar en el que la gente tiene que traer alimento de fuera, donde la vegetación está en macetas y oyes a la gente desde detrás de un tabique no me parece sostenible. Sé que es una visión muy radical...Es la visión de un ermitaño.

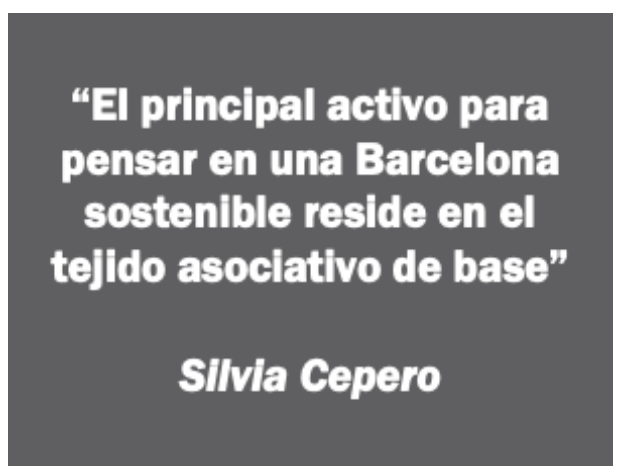

SC: Es cierto que, si existe algún sujeto que se tenga que responsabilizar, tienen que ser las personas que viven en las ciudades, contextos donde es muy difícil afrontar proyectos de sostenibilidad. Sin embargo, por diferentes motivos, existe la necesidad de vivir aquí (aunque entiendo que esto sería cuestionable) y, por tanto, existe la obligación de afrontar los retos de la sostenibilidad. Por tanto, desde mi punto de vista, otra potencialidad sería el sentimiento de responsabilidad que tiene Barcelona como ciudad y, al mismo tiempo, lo que representa sobre una mirada territorial al reto de la sostenibilidad.

Carme Mayugo (CM): Pese al desarrollo de políticas de sostenibilidad, existen comunidades que quedan relegadas a los márgenes. ¿Es posible crear formas de inclusión de estas comunidades que, al mismo tiempo, les permitan desarrollar sus propias propuestas?

DF: Estamos teniendo esta conversación en El Poblenou, 22@ ${ }^{2}$, que es un barrio que no he atravesado desde hace muchos años y no he explorado directamente desde que realizamos Moby Dick (2002) ${ }^{3}$. Paseando de nuevo por este barrio recuerdo que, cuando vivía aquí, Barcelona era una ciudad más dura (pasear en bicicleta, por ejemplo, era imposible) y ahora me parece una ciudad mucho más cómoda. Respecto a la gente que está en los márgenes, yo no la veo. Para mi este era un barrio de gente en los márgenes, un barrio habitado por gente mayor que vivía de modo humilde y que, seguramente, eran jubilados que habían trabajado en el propio barrio. Era un barrio de "gente flotante", que ocupaba espacios y que, en ese momento, yo los denominada "tribus" porque eran grupos relativamente numerosos de familias gitanas, inmigrantes...Ahora mismo, a esta gente no la veo. No veo gente mayor ni gente en el margen. Veo un barrio de gente joven. Entonces me pregunto dónde están las personas que habitaban antes el barrio, ¿se han reubicado en otros puntos de la ciudad?, ¿se ha hecho algo por ellos? Yo no lo sé...No puedo decir nada porque no lo sé. Desconozco si el Ayuntamiento ha hecho algo para afrontar este tipo de cosas o si, directamente, estas personas han desaparecido y han sido expulsadas a lugares mucho más periféricos todavía. 
SC: Ahora estoy en un proceso participativo de decisión en Ciutat Meridiana para hacer un urbanismo táctico que ofrezca otro uso a las plazas y espacios del barrio. Se está llevando a cabo desde el Ayuntamiento, para decidir colectivamente cómo queremos los barrios ${ }^{4}$. Esto nos lleva al dilema que siempre está presente en los procesos participativos: cómo llegas y a qué personas llegas. Además, las personas que vayan a estar en ese proceso participativo, ¿cómo van a sostener esa continuidad que requiere el proceso para decidir las cosas? Por otro lado, existe el problema de la gente en los márgenes, que sigue siendo invisible y que no forma parte ni siquiera de estos procesos participativos, que podrían ofrecer una oportunidad para incluir a estas minorías que se quedan fuera de las decisiones. Yo vivía en el barrio de Gràcia, un barrio masificado por el turismo que se ha convertido en una fachada, una postal y, al mismo tiempo, una zona imposible para vivir. Vivimos procesos de gentrificación permanente que ya no solo afectan al centro, sino que se están extrapolando a Cornellà, L'Hospitalet...Se está extendiendo y, por tanto, alejando también los márgenes...Es un reto pensar cómo incluir a las minorías. Por cierto, se trata de una palabra "minoría" - de la que se ha abusado tanto que ya no sabes qué significa.

DF: Respecto a la cuestión de la participación, también soy muy pesimista. Se me hace muy difícil pensar que puede haber procesos reales de participación que incluyan a todas las personas. Mi experiencia participativa fue en Figaró - con una población de unas mil personas - en una época de cierta gestión participativa del pueblo que, además, fue modelo y pionera y que, sin embargo, ya no funcionaba. El proceso no llegaba a ciertas partes de la población o no se sentían interpeladas por dicho proceso. Intento imaginar cómo podría gestionarse esta participación colectiva en una ciudad y no sé hasta qué punto puede funcionar o, hasta cierto punto, es una manera de generar contenidos y comunicación para dar valor a cosas que, en realidad, no lo tienen tanto.

SC: Tal vez hay un enfoque de "intención sin un cambio de paradigma" en cómo afrontas lo participativo. A partir de mi experiencia en procesos de participación, veo que sigue habiendo una demanda muy enfocada al resultado. En cualquier caso, citando el ejemplo que ponía sobre Ciutat Meridiana, es cierto que muchos vecinos no se han enterado o no quieren participar. Por tanto, cuando queremos hacer algo participativo, ¿cómo lo enfocamos? Generalmente, se hace desde los resultados. Sin embargo, olvidamos el proceso que, en mi opinión, es lo más importante de los procesos participativos. Creo que requiere de un cambio de mirada, en primer lugar, respecto a qué significa lo participativo.

CM: Respecto al papel de las instituciones y servicios públicos, ¿pueden ser activadores de estos procesos o deberían mantenerse en un lugar de escucha de los proyectos iniciados por las comunidades?

SC: Cuando la necesidad viene planteada desde las comunidades resulta más real y viva que cuando proviene de una agenda política e inquietud institucional que, en mi opinión, parece más una imposición que una propuesta. Para mí, claramente, las instituciones deben estar al servicio de la escucha de la necesidad vecinal, y no al revés. Otra cosa es que, en ocasiones, haga falta promover y motivar estas posibilidades o inspirar a las personas en su rol de agentes de cambio de los espacios. En cualquier caso, insisto, las instituciones deben asumir el papel principal de escucha. De otro modo se desvirtúa el sentido de movilizarse desde las necesidades de base. 


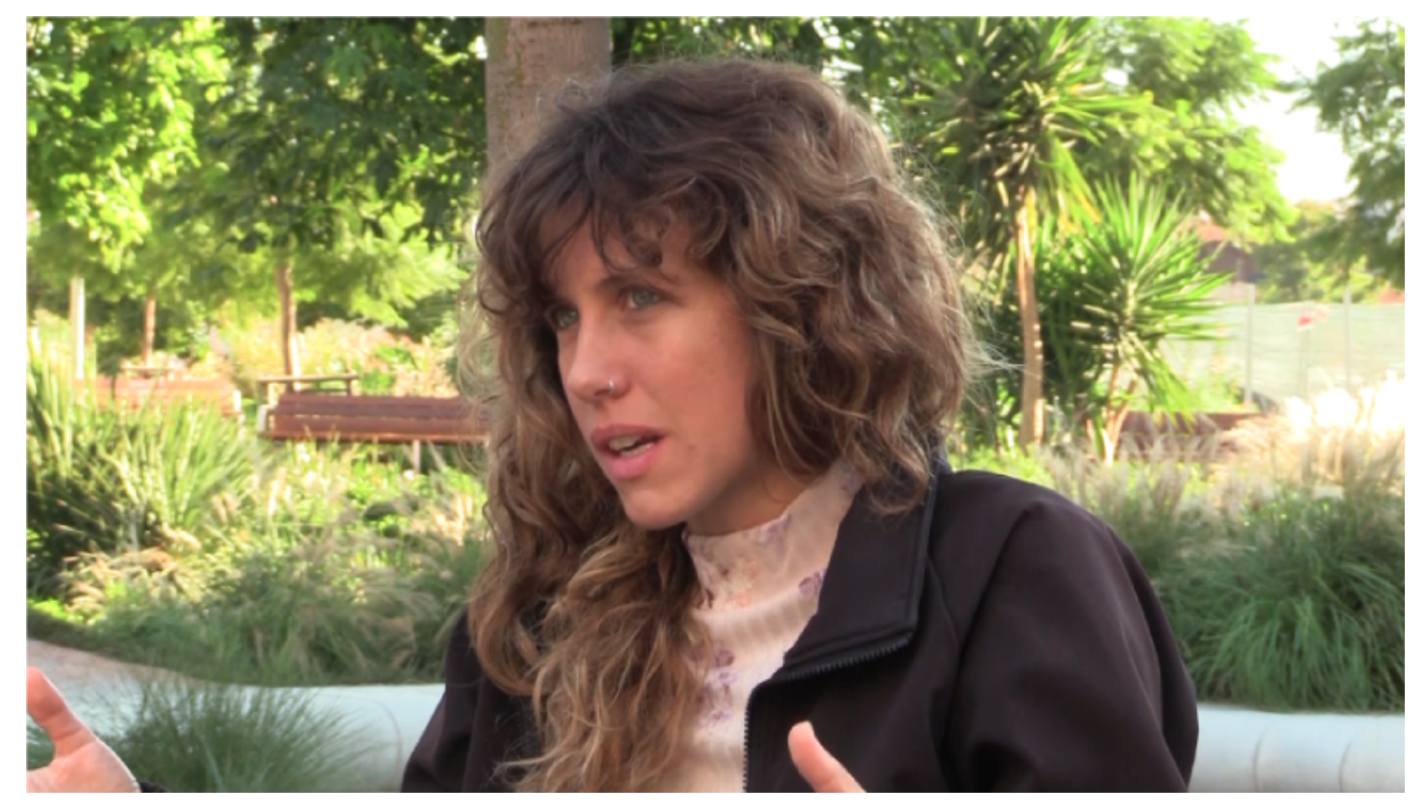

DF: Estoy totalmente de acuerdo. Es la gente la que tiene que crear las condiciones, demandas y proyectos, y las instituciones deben escucharlas. El problema es que esto no funciona así. Pongo como gran ejemplo los propios ODS: una cosa que nadie sabe de qué va, que lleva años sobre la mesa de todo el mundo y que no sirve para mucho...0 sirve para justificar decisiones que son muy sesgadas...Por ejemplo, España decide trabajar temas de género, mientras que otros lugares, como Italia (una realidad que conozco bien), no han promovido nada al respecto. Entonces, cada uno escoge lo que le resulta cómodo y fácil, en lo que puede aportar resultados, pero siempre sin pensar en lo que realmente hace falta: en Italia hacen falta políticas de género mucho más que en España. En realidad, cualquier proyecto que parte desde las instituciones atiende a esta estrategia $\mathrm{y}$, posteriormente, intentan venderlo a las personas para que parezca que estás decidiendo sobre ello. Es un juego.

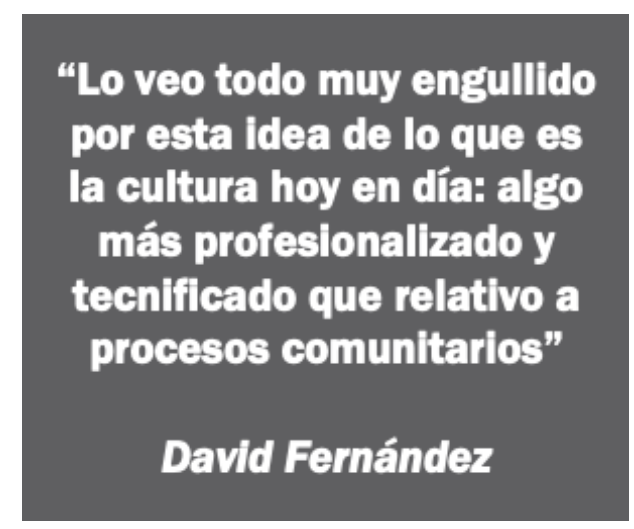

SC: También debemos atender a la cobertura mediática de estas cuestiones: el relato del desarrollo sostenible se propone desde aquello de lo que es posible presumir. Existe poca base crítica. ¿qué relato se hace? ¿cómo se empodera a las personas a liderar procesos de cambio? Efectivamente, concuerdo en que suele ponerse el foco en aquello que resulta más fácil o conveniente. En lo que atañe a ecología y sostenibilidad, por ejemplo, suele señalarse a la ciudadanía 
como responsable de la contaminación, de la carencia de reciclaje, etc. Y, sin embargo, sigue dándose mucho bombo a entidades, normalmente privadas, que siguen estrategias de limpieza de cara desde el discurso de la responsabilidad corporativa.

\section{EL AUDIOVISUAL Y LA CIUDAD COMO PERMANENCIAS}

CM: ¿Puede el audiovisual equilibrar el enfoque y relato hegemónico de los medios dominantes? ¿Existen otros espacios y relatos?

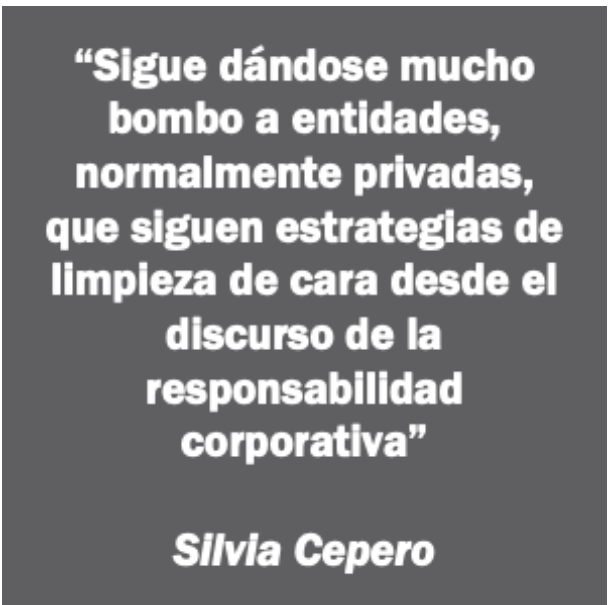

DF: Yo no los conozco, aunque, seguramente, los hay. Sin embargo, en esto también soy escéptico. Creo que la maquinaria de gestión cultural es cada vez más grande y que los espacios donde se puede hablar con cierta autenticidad, o con cierta resistencia, son cada vez más pequeños. Se convierten en invisibles o en alimentos para un circo. Seguramente me estoy perdiendo un tejido cultural que está en lo que en mi época solía llamarse underground, que existe seguro en Barcelona y muchas otras ciudades, pero lo desconozco. Lo que me llega desde fuera es lo que se promueve, y lo que se promueve no es más que una mezcla entre arte y espectáculo que hoy en día se llama cultura y que es un poco lo que sustituye ambas cosas.

SC: Soy un poco más optimista. En mi opinión, el audio-visual es, claramente, el canal y la lengua que hablan las nuevas generaciones. Tenemos la esfera mediática de la industria cinematográfica, donde hay mucha diversidad, pero también toda la autoproducción y creación permanente: Tik Tok, Instagram o YouTube, por ejemplo, que construyen relatos y diversifican las opiniones y realidades. Por otro lado, desde el cine consciente se pueden generar relatos y altavoces que generen un impacto. Es cierto que podemos poner en duda que esto tenga una gran distribución, pero sí confío en estas semillas que pueden promover cambios. Y no solo me refiero a relatos audiovisuales desde del formato documental o no ficción, sino también relatos de ficción con capacidad para generar otros futuros posibles. Generar esperanzas desde la ficción para soñar, revisar realidades o, incluso, realizar ejercicios de memoria histórica. También existen fenómenos mainstream que, incluso desde plataformas como Netflix, Amazon o HBO, entre otras, están visiblizando contenidos que pueden promover cambios. Es la ventana al mundo.

CM: ¿Qué puede aportar un audiovisual de autoproducción, más participativo y, en cierta medida, realizado "a fuego lento"? 
DF: Es un aprendizaje personal. No creo que sirva para mucho más. Ahora mismo estoy en un proyecto relativamente grande con un amigo que, seguramente, diría que estamos haciendo algo muy importante con capacidad para cambiar perspectivas. Él está convencido y pensando en festivales. Yo lo vivo de otra manera, no creo que tenga mucha trascendencia. Seguramente esto también es parte de mis incapacidades. No soy muy optimista. Moby Dick fue una experimentación y me sorprende que, siendo un documental con una absoluta voluntad de permanecer en el underground, casi 20 años después sirva a algunas personas para señalar que existió un Poblenou que desconocían: una realidad, un tipo de barrio que parece que esté borrado de la memoria, ya no digo de las personas, sino de la ciudad. Pero es una exclamación de personas que luego se van a otras cosas. No parece que esté cambiando nada descubrir esa realidad perdida. Si la cuestión es valorar si un trabajo de este tipo puede influir de una manera perceptible en algún cambio, o en reconocer un daño, que podría ser el caso de Moby Dick, yo diría que no. En este sentido, incluso, seguramente hace más bien una serie de Netflix. 0 mucho más mal.

CM: El audiovisual puede generar ese espacio de permanencia...

DF: De permanencia en la memoria. Pero, ¿para qué sirve? Viendo este barrio, pienso que se hace más que nunca. No sé hasta qué punto puedes canalizar ciertos derechos con una película o ciertas reivindicaciones. No sé si lo haces desde el tipo de cine que yo conozco: un tipo de cine autoproducido con voluntad de experimentación en el lenguaje y la forma...Seguramente hay otros modos.

SC: Pretender que una película, o cien, lo cambien todo, no es suficiente. Me vienen a la cabeza producciones de ACATS, como Nosotros No Olvidamos $(2020)^{5}$, y creo que hacen una labor que puede llegar a trascender y a movilizar a una red más amplia que aquellas personas que forma parte de la propia expresión creativa. Lo que traen los procesos de creación colectiva es que el propio proceso ya es una vivencia, quizás no en un sentido masivo de gran impacto, pero sí un impacto positivo. Pienso en el grupo de mujeres con las que hice el documental Blessy $(2018)^{6}$, supervivientes del tráfico de personas, y entre ellas y su constelación hubo una semilla de algo que ha servido, a partir del propio proceso creativo, para autorepresentarse desde otro lugar. Y no solo se trata del cine participativo, sino de procesos de transformación de la propia industria. En este sentido, como socia de Dones Visuals ${ }^{7}$, tengo la experiencia de procesos que están impulsado la introducción de la perspectiva feminista en la producción y el contenido audiovisual. En el Festival de San Sebastián, por ejemplo, se plantearon, a través de una Carta Abierta, reclamaciones para exigir a los festivales que exista cierta cuota de mujeres, que ocupen cargos importantes en el mundo audiovisual $y$, además, que se aplique una perspectiva de género en el ámbito de las identidades sexuales. En definitiva, sí creo que el audiovisual puede generar pequeños impactos importantes a distintas escalas. 


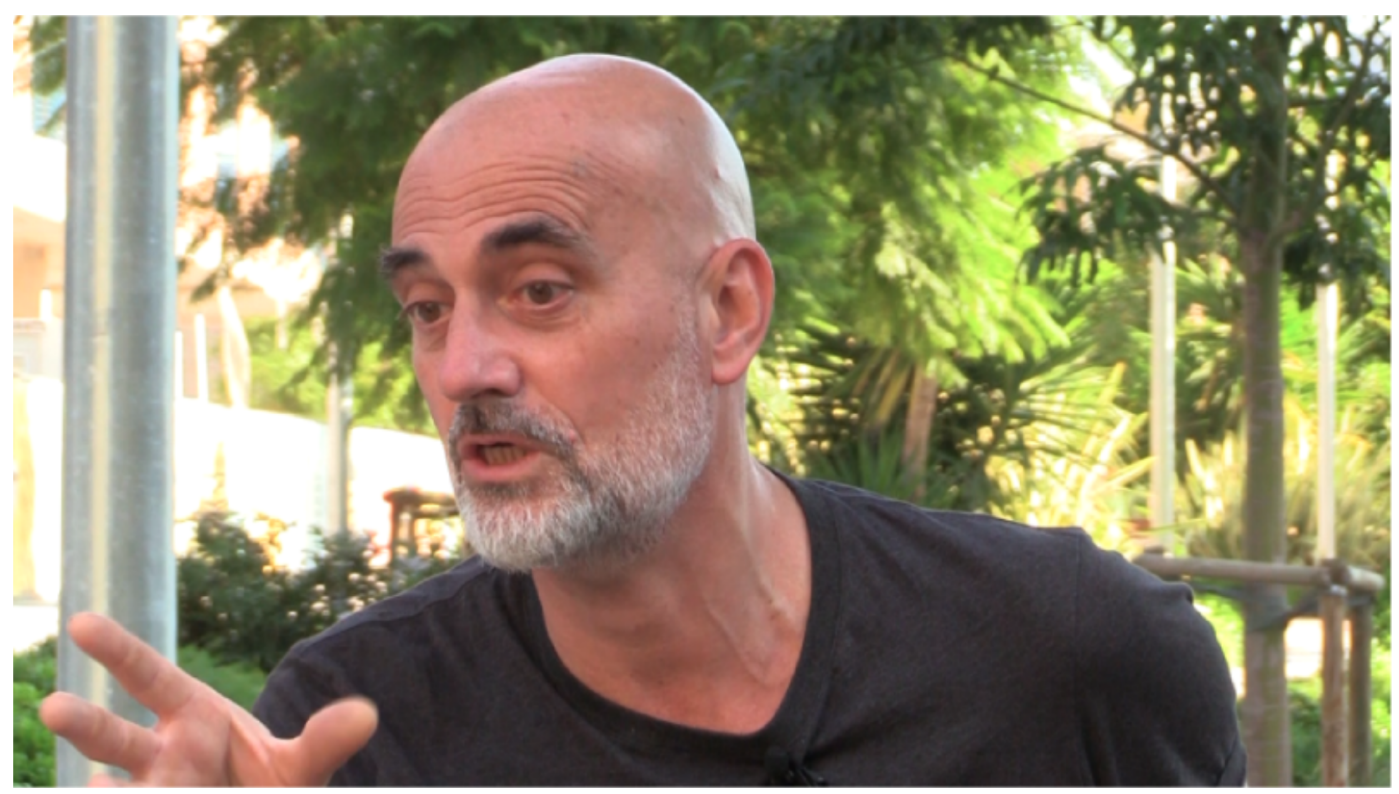

DF: En eso estoy de acuerdo. La experiencia de construir un relato audiovisual es válida en tanto experiencia. En tanto a producto terminado y recibido tengo mis dudas. En este sentido, creo que las pocas o pequeñas grandes cosas que yo he conseguido hacer en el ámbito de los procesos participativos de pequeños colectivos han tenido mucho valor (como procesos, desde luego). Sin embargo, luego lo veo todo muy engullido por esta idea de lo que es la cultura hoy en día. Yo creía que la cultura era lo que tejía la sociedad, lo que definía y diferenciaba un grupo de otro desde una perspectiva, además, de base: tiene incluso que ver con la cultura que hay dentro de una fábrica, por ejemplo. Hoy en día esto no es cultura, que se interpreta más con algo mucho más profesionalizado o, al menos, tecnificado, que implica que tienes acceso a ciertos elementos técnicos (teléfonos, cámaras, acceso a internet, etc.). En este mecanismo de lo que se entiende por cultura hoy, creo que la vivencia que podamos tener respecto al producto que deriva de un proceso se pierde mucho. Moby Dick, por ejemplo, es una película que representa mucho tiempo de muchas personas que, de alguna manera, vieron valorada su vida hasta el punto de que tenía, incluso, una cierta mítica. Eso es el proceso, y para mi tiene mucho valor. Es una película que te cambia. El hecho de hacerla sin medios, sin ninguna voluntad lucrativa, hace que, por ejemplo, un programador esté actualmente programándola contra mi voluntad, haciéndola suya sin haber dedicado ni media hora a vivir esa experiencia. Y puede utilizarla para sus intereses dentro de una argumentación con la que yo no esté de acuerdo.

CM: ¿Podríais destacar una experiencia en la que hayáis utilizado el audiovisual como una herramienta para generar procesos nuevos, cambiar cosas y que os haya marcado de forma particular?

DF: Yo tengo mucho cariño por una cierta parte de mi vida, en plena resaca tras la crisis de 2008, en la que, en diferentes ámbitos, aunque casi todos municipales y de pueblos pequeños, hacíamos pequeños talleres de videocurrículum (unas 10 personas por taller) para parados de larga duración, gente que nunca había tenido empleo, inmigrantes, etc. Fue una experiencia muy bonita donde realmente el grupo gestionaba todo, había mucha implicación y, además, se consiguió un índice de ocupación altísimo: un 60\% - 70\% de ocupación tras los talleres. Fue algo que realmente sirvió mucho a la gente y fue un proceso bonito. Las piezas son bonitas y pudimos compartir el entusiasmo 
y la alegría de muchas personas al realizar el proceso y conseguir trabajo. Las piezas son bonitas porque las personas son muy bonitas.

SC: Me vienen a la cabeza dos momentos diferentes. El primero quizás no tenga tanto que ver con la promoción de un proceso de creación colectiva, pero sí con la organización de un tejido de medios alternativos de base con videoactivistas, que fue en la época tras la crisis de 2008 con la Agència 29$S^{8}$. Conseguimos generar procesos de contrainformación en espacios de lucha en un momento de tensión, huelgas generales y manifestaciones. Creo que se consiguió generar otro relato del impacto de las movilizaciones en la calle. Por otro lado, pensando en un proceso de creación colectiva, podría señalar, entre otros, el documental Viure al limit $(2017)^{9}$, porque los documentales son los procesos de participación más largos, y también porque me parece interesante abordar el guion, la idea, el relato y la autorepresentación de un grupo de personas que tienen un diagnóstico de inteligencia límite y que, por tanto, su manera de codificar y autoexpresarse era un reto permanente que, además, exigía reflexionar continuamente cómo pensamos y aquello que damos por sentado. Recuerdo un ejercicio en el que trabajábamos el sentido de agencia y poder en una dinámica de teatro y, de golpe, estas personas afirmaban que en ninguna esfera de su vida sentían que tenían poder salvo en el propio proceso de participación en el documental.

CM: Hay personas que pueden formar parte de procesos participativos a partir de este tipo de proyectos. El audiovisual nos permite sumar realidades...

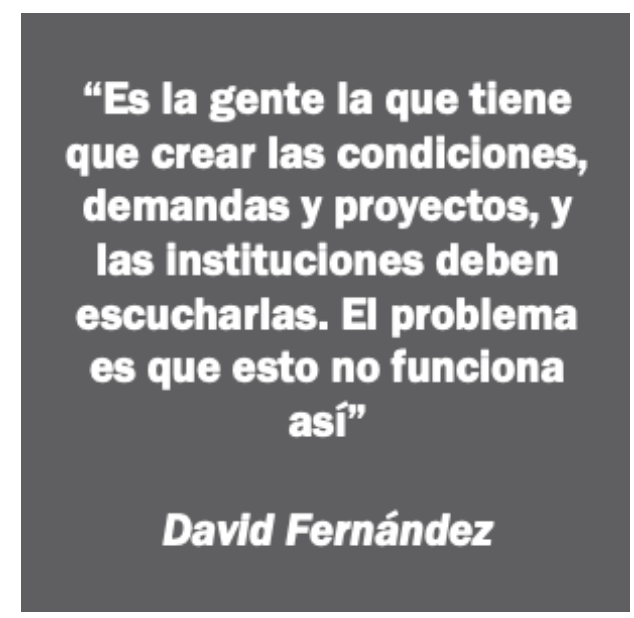

DF: Lo bonito de hacer audiovisual participativo es, precisamente, dar voz a otras personas. Son procesos difíciles porque hay que conciliar el proceso con ciertas exigencias de calidad y formato.

SC: Con Blessy comenzamos haciendo un taller de autobiografías con mujeres supervivientes de trata de personas que refleja perfectamente la necesidad de visibilizar y relatar otras miradas. El proceso de construcción autobiográfica a través de collage y animación permite entender la importancia del audiovisual a la hora de mostrar estas realidades a través de distintos formatos de creación artística, y no solo desde las formas habituales de representación audiovisual. En el caso de Blessy, por ejemplo, no utilizamos el formato tradicional de mostrar a las personas en la sombra, con la voz distorsionada, sino que, a través de otro tipo de proceso creativo, conseguimos mostrar relatos en primera persona manteniendo el protagonismo de las personas involucradas en el proceso.

DF: Yo soy un narrador y vivo de estructurar relatos. Siempre con herramientas visuales. Soy un poco el bufón de la corte $y$, en ese hacer de bufón, puedo acercarme a la gente para darle valor a 
su experiencia. Cuando vuelvo a encontrarme con gente con la que he compartido estos procesos colectivos, sin embargo, no observo interés por su parte respecto al audiovisual o respecto a generar más contenidos audiovisuales. Seguramente, sin que se den cuenta, al haber tenido la oportunidad de manejar de primera mano el lenguaje audiovisual, desarrollen una mirada más crítica respecto a otros productos similares. Algo quedará, seguro.

SC: En procesos largos queda siempre la experiencia y la pieza. Es una cuestión compleja. Yo me quedo con todo lo que he podido aprender, escuchar, debatir y representar. En mi caso, he llevado la creación audiovisual al terreno de la facilitación: me interesaba aportar herramientas que nos ayuden a entender mejor lo que nos sucede como colectivo, generar debates más profundos, visibilizar estructuras de poder...En cualquier caso, sin ninguna pretensión de afirmar que sea yo la que aporta todas estas cosas, sino formar parte del proceso que habilita todas estas posibilidades. Me gustaría pensar que estos procesos han servido para reflexionar y sentir desde un lugar diferente. Me faltaría perspectiva para poder nombrar todo lo que me llevo de estos procesos. Está todavía en construcción. La palabra es siempre proceso, más que resultados. Es lo que me gusta de la creación.

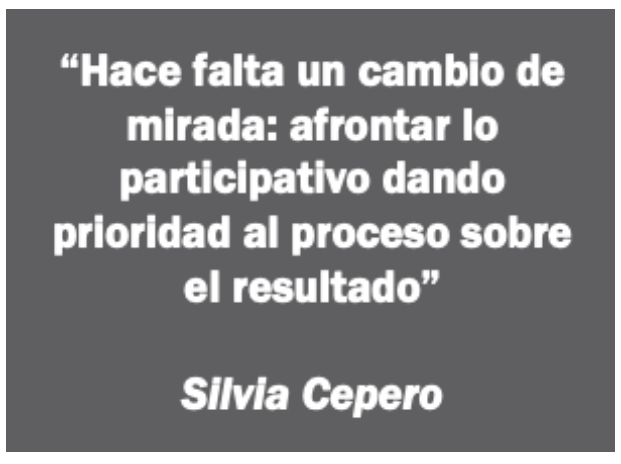

DF: Durante algunos años hice una serie de talleres de carpintería y pintura con adolescentes que venían de situaciones complicadas. En la caja de herramientas había una pequeña cámara de vídeo. Yo siempre decía: "Eso es una herramienta. Si alguien no sabe qué hacer, que la coja y grabe a los demás". Esta historia me recuerda lo importante de entender el audiovisual como proceso, y no como resultado, aplicado a la propia textura de la imagen audiovisual (que es una cuestión de desarrollo temporal en un espacio de cosas). El hecho de grabarse realizando determinadas tareas hacía que estos adolescentes se dieran cuenta de la importancia del propio proceso de trabajo que estaban realizando (cortar una madera, por ejemplo) y no solo del resultado final. Cuando veían la grabación, lo menos importante de todo era el resultado (la madera cortada), ya que lo que importaba era ver reflejado el propio proceso de estar cortando la madera. Esto te hace más consciente de que debes estar presente viviendo las cosas y, en realidad, el momento de terminar "la cosa" es nada, un resultado, que no tiene duración siquiera.

SC: Esto es muy interesante. A las creadoras y creadores, como demanda, cada vez nos piden más proyectos desde la óptica de los resultados. El planteamiento de la demanda incluye el resultado. Esto es un problema y, al mismo tiempo, es algo paradigmático: vivimos en la perspectiva del resultado. Es una pena y, al mismo tiempo, debe ser una lucha y reivindicación del cine de creación participativo. 
Sostenibilidad y participación ciudadana: el audiovisual como proceso de creación y transformación colectiva. Una conversación entre David

Fernández y Silvia Cepero

\section{NOTAS}

* Jorge Llanes es magister en Servicios Culturales, especializado en Gestión de Bienes Comunes, por la USC y magister en Radio por la URJC. Graduado en Periodismo por la UPS ha trabajado en diversas emisoras radiofónicas y agencias publicitarias, además de haber dinamizado grupos de voluntariado cultural. Es colaborador de RICD.

Contacto: jllanesjo@gmail.com

** Carme Mayugo es doctora en Ciencias de la Comunicación por la USC y licenciada en Ciencias de la Información por la UAB. Directora de Teleduca, colectivo especializado en proyectos educomunicativos, es formadora en diversos proyectos locales e internacionales sobre audiovisual participativo, comunicación comunitaria, documental de autoproducción y pedagogías críticas.

Contacto: teleduca@teleduca.org

*** David Fernández es especialista en narrativas visuales e ilustrador. Director artístico y montador en diversos largometrajes ha ejercido como profesor de documental y de lenguaje audiovisual. Ha realizado numerosos talleres para proyectos participativos y de autorepresentación.

Contacto: tornadeira@gmail.com

**** Silvia Cepero ha realizado estudios de Comunicación y de Documental y Género. Cofundadora de Càmeres i Acció ha montado y dirigido documentales como Virus (2013), Rap en la Trajana (2014), Retratos sin techo (2014) y Puzzle (2015). En la actualidad coordina varios proyectos audiovisuales de intervención social. Ha trabajado en medios de comunicación comunitarios e independientes como periodista, realizadora y montadora.

Contacto: ceperosilvia@gmail.com

1 En la grabación de esta conversación han intervenido como equipo técnico David Campillo, Matilde Molnar y Sebastián di Siervo, de Teleduca.

2 El Distrito 22@ (también conocido como 22@Barcelona o 22@) se implantó en el año 2000 como una iniciativa del Ayuntamiento de Barcelona para reconvertir 200 hectáreas del antiguo suelo industrial del barrio de Poblenou en un espacio empresarial dedicado a la innovación tecnológica.

3 Documental realizado por David Fernández y Jordi Vera en 2001, estrenado en 2002 en el Festival L'Alternativa de Barcelona, que aborda la realidad de El Poblenou en la Barcelona posindustrial.

4 Se trata del fomento de procesos participativos desde la a plataforma decidim.barcelona. Puede verse aquí: $\underline{h}$ ttps://www.decidim.barcelona/?locale=es

5 ACATS es una productora audiovisual autogestionada que reivindica la "desobediencia cultural". Puede consultarse su página web aquí: https://acats.cat/qui-som/. Nosotros No Olvidamos es un documental producido 2020 que narra la historia de Pedro Álvarez, un joven de 20 años de la Verneda, que fue asesinado en l'Hospitalet de Llobregat en una discusión de tráfico a manos de un Policía Nacional.

6 Blessy es un documental social participativo, producido por Càmeres i Acció y La Ròtula con la colaboración de SICAR cat. Se trata de una creación colectiva que narra la experiencia de cuatro mujeres supervivientes de la trata de personas.

7 Asociación fundada en 2017 como Associació Promotora de Dones Cineastes i de Mitjans Audiovisuals de Catalunya (Asociación Promotora de Mujeres Cineastas y de Medios Audiovisuales de Cataluña) para defender, promover y hacer efectiva la presencia de las mujeres en el sector audiovisual.

8 Coordinadora independiente de medios alternativos creada para cubrir la Huelga General del 29 de septiembre de 2010.

9 Documental social participativo realizado por seis personas con un diagnóstico de inteligencia límite. Se trata de una producción conjunta de Càmeres i Acció y la Fundación Acidh. 